Joost J. Zwart

Just R. O. Dupuis

Annemiek Richters

Ferko Öry

Jos van Roosmalen

\section{Obstetric intensive care unit admission: a 2-year nationwide population-based cohort study}

Received: 25 February 2009

Accepted: 15 July 2009

Published online: 10 November 2009

(C) The Author(s) 2009. This article is published with open access at

Springerlink.com

\section{J. J. Zwart (四) J. R. O. Dupuis ·}

J. van Roosmalen

Department of Obstetrics, K6-P-35, Leiden

University Medical Centre, P.O. Box 9600, 2300 RC Leiden, The Netherlands

e-mail: j.j.zwart@lumc.nl

\section{A. Richters}

Department of Public Health and Primary Care, Leiden University Medical Centre, Leiden, The Netherlands

F. Öry

Department of Public Health, TNO Prevention and Health,

Leiden, The Netherlands

F. Öry

Pacemaker in Global Health,

Amsterdam, The Netherlands

J. van Roosmalen

Section of Culture and Health Care,

VU University Medical Centre,

Amsterdam, The Netherlands
Abstract Purpose: As part of a larger nationwide enquiry into severe maternal morbidity, our aim was to assess the incidence and possible risk factors of obstetric intensive care unit (ICU) admission in the Netherlands. Methods: In a 2-year nationwide prospective population-based cohort study, all ICU admissions during pregnancy, delivery and puerperium (up to 42 days postpartum) were prospectively collected. Incidence, case fatality rate and possible risk factors were assessed, with special attention to the ethnic background of women. Results: All 98 Dutch maternity units participated in the study. There were 847 obstetric ICU admissions in 358,874 deliveries, the incidence being 2.4 per 1,000 deliveries. Twenty-nine maternal deaths occurred, resulting in a case fatality rate of 1 in $29(3.5 \%)$. Incidence of ICU admission varied largely across the country. Thirty-three percent of all cases of severe maternal morbidity were admitted to an ICU. Most frequent reasons for ICU admission were major obstetric haemorrhage
(48.6\%), hypertensive disorders of pregnancy (29.3\%) and sepsis (8.1\%). Assisted ventilation was needed in $34.8 \%$, inotropic support in $8.8 \%$. In univariable analysis, non-Western immigrant women had a 1.4 -fold (95\% CI 1.2-1.7) increased risk of ICU admission as compared to Western women. Initial antenatal care by an obstetrician was associated with a higher risk and home delivery with a lower risk of ICU admission.

Conclusions: Population-based incidence of obstetric ICU admission in the Netherlands was 2.4 per 1,000 deliveries. Obstetric ICU admission accounts for only one-third of all cases of severe maternal morbidity in the Netherlands.

Keywords Pregnancy · Intensive care unit - Severe maternal morbidity · Maternal mortality . Nationwide Incidence

\section{Introduction}

Pregnancy, delivery and puerperium can be complicated by severe maternal morbidity necessitating intensive care unit (ICU) admission. Management of the critically ill obstetric patient is very complex and requires cooperation of both obstetrician and intensivist/ anaesthetist. One facility-based study has been performed in the Netherlands, which reported an incidence of 7.6 per 1,000 deliveries [1]. However, this study was inevitably biased by the long (12-year) inclusion period, during which technological and therapeutic changes have occurred. Moreover, it was held in a tertiary care centre only. 
The primary aim of this study was to assess incidence, case fatality rate and possible risk factors of obstetric ICU admission on a population-based national level. As ethnicity appeared to be a significant risk factor for severe maternal morbidity and maternal death, we were especially interested in the association of ethnicity with obstetric ICU admission [1-3].

\section{Methods}

This study was part of a broader nationwide enquiry into severe maternal morbidity in the Netherlands, called LEMMoN [4]. In this study, which enrolled cases from 1 August 2004 until 1 August 2006, all Dutch hospitals with an obstetric unit participated. This involves 10 tertiary care centres, 33 non-academic teaching hospitals and 55 general hospitals. There is no private obstetric care in the Netherlands. All hospitals with an obstetric unit are equipped with an ICU, subdivided into three levels. Level 1 ICUs are equipped for monitoring and treatment of patients with single organ dysfunction, if necessary with assisted ventilation. Patients with severe diseases can be monitored and treated at level 2 ICUs, and level 3 ICUs are equipped for patients with very complicated diseases with multiple organ dysfunction who need constant availability of an intensivist. According to the Netherlands Health Care Inspectorate, there are 49 level 1 units, 25 level 2 units and 24 level 3 units in the Netherlands [5]. In addition to a level 3 ICU, all tertiary care centres are also equipped with an obstetric high care unit, which has one-to-one nursery care and cardiac monitoring, but no assisted ventilation. There are no special obstetric ICUs in the Netherlands. Forty-one percent of all deliveries are considered low-risk pregnancies and take place under the responsibility of primary care providers, three quarters of which are home births. Any complication occurring in primary care will be referred to a hospital and thus be notified. ICU admission was defined as admission to an ICU or coronary care unit, but not to an obstetric high care unit. Short stay at an ICU only because of postoperative nursery was not considered as an ICU admission.

Requests for notification of cases of obstetric ICU admission during pregnancy, delivery or puerperium were, along with other types of severe maternal morbidity, sent to all local coordinators on a monthly basis. Cases were communicated to the National Surveillance Centre for Obstetrics and Gynaecology (NSCOG) in a web-based design. If no cases of obstetric ICU admission occurred, this was also reported. Reminders were sent to non-responders every month until they had returned the monthly notification card.

After notification, a completed case record form was sent to us, accompanied by anonymous photocopies of all relevant sections of the hospital case notes and correspondence. A detailed review of cases was completed by two of the authors (JZ and JD), and all cases were entered into an Access database. Cases of maternal mortality were reported to the national Maternal Mortality Committee of the Netherlands Society of Obstetrics and Gynaecology by the attending obstetrician as usual. These cases were eventually added to the database.

We recorded maternal characteristics (age, body mass index, parity, ethnicity, smoking), and all variables concerning pregnancy and delivery. We also recorded data specifically related to the ICU admission: admission and discharge date, diagnosis on admission, vital signs on admission, interventions and laboratory results. A total of 150 items were entered into the database for each case. Characteristics of each hospital were also recorded (university or teaching hospital, annual number of deliveries and level of ICU). Major obstetric haemorrhage (MOH) was defined as transfusion need of four or more units of packed cells or hysterectomy or embolisation. When more than one diagnosis was provided, the case was classified according to the most serious condition.

Ethnicity was defined by country of origin ('geographical ethnic origin') and grouped according to the most common population groups in the Netherlands (Western, Moroccan, Surinam/Dutch Antilles, Turkish, sub-Saharan African and Central and Eastern Asian). Women born in the Netherlands with at least one parent born abroad were considered to be from the same origin as their non-Dutch parent(s). Women from other European countries, North America, Japan and Indonesia were considered Western immigrants according to Statistics Netherlands because of their cultural background and socio-economic position, which is comparable with Western women. All other immigrant women were considered non-Western.

Denominator data for the number of births in the Netherlands and national reference values for possible risk factors for obstetric ICU admission were obtained from Statistics Netherlands and The Netherlands Perinatal Registry (LVR-2) [6, 7]. The case fatality rate was calculated by dividing the number of deaths by the total number of ICU admissions. Relative risks and confidence intervals compared with the general pregnant population were calculated using univariable analysis. Odds ratios and confidence intervals compared with women with severe maternal morbidity not admitted to the ICU were calculated using multivariable logistic regression analysis. Differences between groups were identified using the chi-square test; significance was defined as $p<0.05$. Statistical analysis was performed using Statistical Package for the Social Sciences (SPSS 16.0). The study was centrally approved by the medical ethics committee of Leiden University Medical Centre. 


\section{Results}

Incidence

During the study period, 371,021 deliveries occurred in the Netherlands. Of all 2,352 (98 hospitals, 24 months) monthly notification cards, $97 \%$ were returned. Therefore, the study represents 358,874 deliveries in the Netherlands. A total of 2,552 cases of severe maternal morbidity were reported to LEMMoN. Of those, 847 cases $(33.2 \%)$ concerned ICU admissions. We received no detailed data in 10 cases, leaving a total of 837 cases available for analysis. Characteristics of women are shown in Table 1. The population-based incidence of obstetric ICU admission was 2.4 per 1,000 deliveries.

Incidence varied largely by hospital, ranging from 0 to 13.2 per 1,000. The mean 'hospital-incidence', considering only births in that hospital under responsibility of the obstetrician and thus disregarding births under primary care, was 3.8 per 1,000 overall, 8.7 for tertiary care centres and 3.4 for general hospitals $(p<0.05)$. Regarding only non-academic hospitals, low-volume $(<1,000$ deliveries $)$ units had an incidence of 4.1 per 1,000 , intermediatevolume (1,000-1,500 deliveries) units 2.4 per 1,000 and high-volume $(>1,500$ deliveries $)$ units 3.3 per 1,000 . The incidence of ICU admission was significantly increased in low-volume hospitals as compared to other non-academic hospitals $(p<0.05)$ and significantly lower in intermediate-volume hospitals as compared to other hospitals $(p<0.001)$. In tertiary care centers, $20.2 \%$ of women were referred from other hospitals. In non-academic teaching

Table 1 Characteristics of women in the study

\begin{tabular}{lrr}
\hline & $n$ & $\%$ \\
\hline Age (years, $n=837)$ & 13 & \\
$<20$ & 579 & 69.6 \\
$20-34$ & 201 & 24.0 \\
$35-39$ & 44 & 5.3 \\
$\geq 40$ & & \\
Body mass index $\left(\mathrm{kg} / \mathrm{m}^{2}, n=547\right)$ & 28 & 5.1 \\
$<18.5$ & 320 & 58.5 \\
$18.5-24.9$ & 114 & 20.8 \\
$25-29.9$ (overweight) & 45 & 8.2 \\
$30-34.9$ (obese) & 40 & 7.3 \\
$\geq 35($ morbidly obese) & & \\
Chronic disease $(n=837)^{\mathrm{a}}$ & 603 & 72.0 \\
No disease & 234 & 28.0 \\
One or more diseases & 47 & 5.6 \\
Hypertension & 34 & 4.1 \\
Chronic obstructive pulmonary disease & 29 & 3.5 \\
Cardiac disease & 21 & 2.5 \\
Thrombosis/clotting disorder & 17 & 2.0 \\
Diabetes & 120 & 14.3 \\
Other & & \\
\hline
\end{tabular}

${ }^{\text {a }}$ Numbers do not add up to the total as women could suffer from more than one disease

b Psychiatric disorders, migraine, autoimmune, thyroid and kidney diseases, epilepsy and malignancies hospitals $4.3 \%$ were referred from other hospitals. Differences by ICU level are shown in Table 2 .

Rates of ICU admission for different subgroups of severe maternal morbidity were $12 \%$ for uterine rupture, $42 \%$ for eclampsia and $27 \%$ for major obstetric haemorrhage. Twenty-six women (3.1\%) were admitted to ICU during early pregnancy, 191 (22.8\%) antepartum and 620 (74.1\%) postpartum. Mean duration of ICU stay was 2.9 days (range 1 to 71 ). Ninety-one women (10.9\%) stayed in the ICU for more than 4 days. Mean gestational age at admission was 36 weeks and 3 days. Of all women, $234(28.0 \%)$ had at least one chronic disease (Table 1). Forty women $(4.8 \%)$ had multiple chronic diseases.

\section{Diagnoses at admission}

Diagnoses at admission are shown in Fig. 1. Cerebral disease and thrombo-embolism had the highest case fatality rates with 26.3 and $23.1 \%$, respectively. Regarding only antepartum diagnoses, $47.6 \%$ of women were diagnosed with hypertensive disorders of pregnancy, $13.6 \%$ with $\mathrm{MOH}$ and $9.9 \%$ with sepsis. Women admitted postpartum were mainly diagnosed with $\mathrm{MOH}(55.2 \%)$ and hypertensive disorders of pregnancy $(21.5 \%)$. Most frequent diagnoses during early pregnancy were $\mathrm{MOH}(50.0 \%)$ and sepsis (26.9\%), mostly caused by ectopic pregnancy or abortion. Regarding differences between hospitals, MOH (39.9 vs. $47.4 \%$ ) and hypertensive disorders of pregnancy (16.8 vs. $30.0 \%$ ) were less diagnosed in tertiary care centers as compared with general hospitals. Rare life-threatening diseases like cardiac, liver/pancreatic, cerebral, septic and thrombo-embolic diseases were more frequently diagnosed in tertiary care centres (33.2 vs. $13.8 \%$ ). Roughly the same results were found for high-volume hospitals in comparison with low-volume hospitals.

\section{Interventions during ICU stay}

Assisted ventilation was needed in 291 women (34.8\%), inotropic support in $74(8.8 \%)$ and renal dialysis in 16 (1.9\%). Central venous and Swan Ganz catheter insertion were reported in $123(14.7 \%)$ and 21 (2.5\%) women, respectively. Packed cells were transfused in 505 women (60.3\%, range 1-50). Fresh frozen plasma and pooled platelets were administered in $365(43.6 \%)$ and 220 (26.3\%) women, respectively. In $82(9.8 \%)$ and 92 $(11.0 \%)$ cases, arterial embolisation and hysterectomy were performed because of $\mathrm{MOH}$.

\section{Possible risk factors of ICU admission}

Non-Western women had a higher risk of being admitted to ICUs than Western women. Especially 
Table 2 Characteristics of admission by intensive care unit level

\begin{tabular}{|c|c|c|c|c|c|c|c|}
\hline & \multicolumn{2}{|c|}{ Level 1} & \multicolumn{2}{|c|}{ Level 2} & \multicolumn{2}{|c|}{ Level 3} & \multirow[t]{2}{*}{$p$ Value } \\
\hline & $n$ & $\%$ & $n$ & $\%$ & $n$ & $\%$ & \\
\hline Number of women admitted to $\mathrm{ICU}^{\mathrm{a}}$ & 266 & 35.6 & 230 & 35.1 & 341 & 29.7 & 0.01 \\
\hline Mean duration of ICU stay (days) & $1.9^{\mathrm{b}}$ & & $2.3^{\mathrm{c}}$ & & $3.2^{\mathrm{d}}$ & & \\
\hline Maternal mortality & 4 & 1.5 & 10 & 4.3 & 15 & 4.4 & 0.11 \\
\hline Induction of labour & 83 & 31.2 & 70 & 30.4 & 86 & 25.2 & 0.20 \\
\hline Inotropic support & 10 & 3.8 & 18 & 7.8 & 46 & 13.5 & $<0.001$ \\
\hline Assisted ventilation & 32 & 12.0 & 87 & 37.8 & 172 & 50.4 & $<0.001$ \\
\hline \multicolumn{8}{|l|}{ Diagnosis } \\
\hline Major obstetric haemorrhage & 110 & 41.4 & 120 & 52.2 & 151 & 44.3 & 0.05 \\
\hline Hypertensive disorders of pregnancy & 111 & 41.7 & 46 & 20.0 & 67 & 19.6 & $<0.001$ \\
\hline Cardiac disease & 8 & 3.0 & 19 & 8.3 & 28 & 8.2 & 0.02 \\
\hline Sepsis & 12 & 4.5 & 16 & 7.0 & 27 & 7.9 & 0.23 \\
\hline Pulmonary disease & 6 & 2.3 & 12 & 5.2 & 25 & 7.3 & 0.02 \\
\hline Cerebral disease & 2 & 0.8 & 3 & 1.3 & 14 & 4.1 & 0.01 \\
\hline Liver/pancreatic disease & 4 & 1.5 & 2 & 0.9 & 8 & 2.3 & 0.39 \\
\hline Thrombo-embolism & 2 & 0.8 & 4 & 1.7 & 7 & 2.1 & 0.42 \\
\hline Anaesthetic complication & 3 & 1.1 & 4 & 1.7 & 5 & 1.5 & 0.85 \\
\hline Miscellaneous & 8 & 3.0 & 4 & 1.7 & 9 & 2.6 & 0.65 \\
\hline
\end{tabular}

Intensive care unit levels are described in the "Methods" $\quad$ c Data missing for 21 women

${ }^{a}$ Rates reflect percentage of all women with severe maternal ${ }^{\mathrm{d}}$ Data missing for 20 women morbidity

${ }^{b}$ Data missing for 22 women

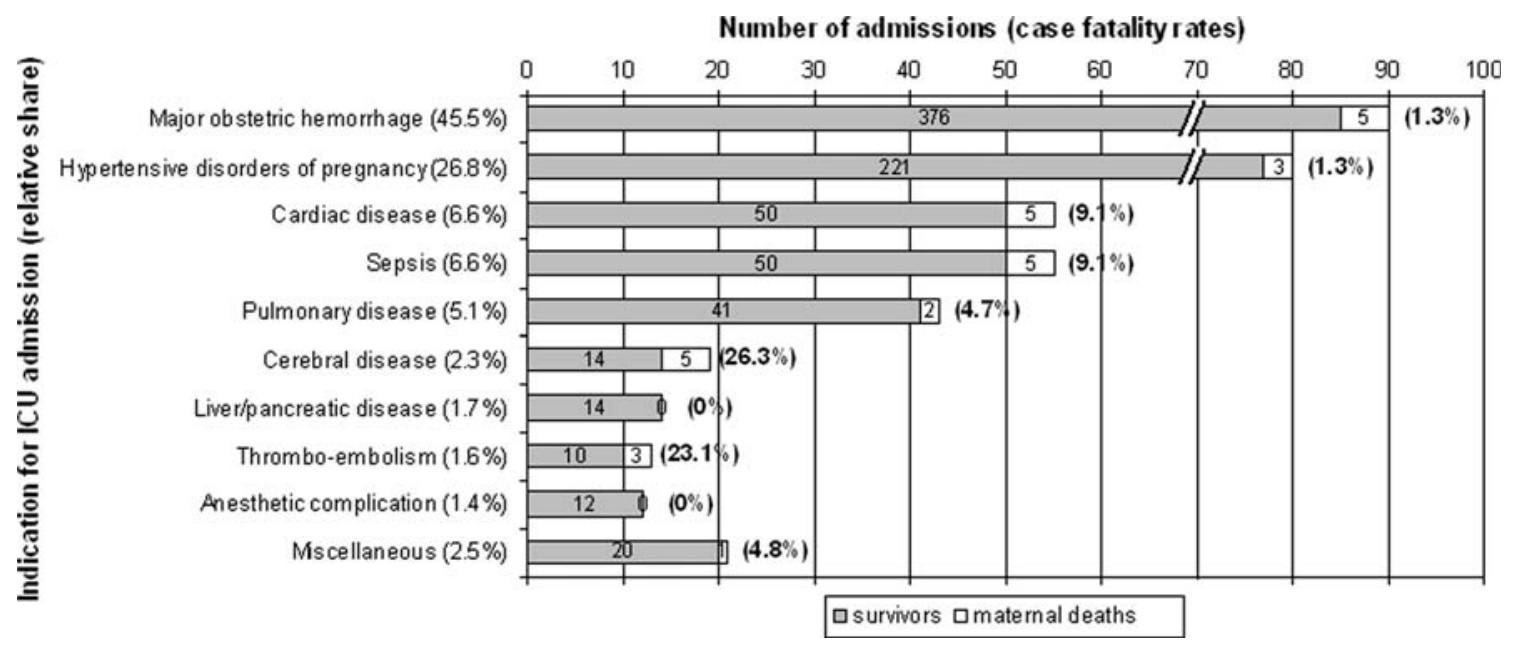

Fig. 1 Outcome of ICU admission by indication for admission

women from sub-Sahara Africa and Eastern Asia Maternal deaths experienced increased risks of ICU admission (Table 3). Other possible risk factors for ICU admission There were 29 maternal deaths during ICU stay, giving a as compared with the general pregnant population and with women with severe maternal morbidity not admitted to the ICU are shown in Table 4. A continuum of risk can be observed from lower risks in the general pregnant population to higher risks among women with severe maternal morbidity and highest risks among women with severe maternal morbidity admitted to ICU.

case fatality rate of 1 in 29 (3.5\%).

Underlying causes of death and case fatality rates by diagnosis on admission are shown in Fig. 1. The most frequent mode of death was cerebral (cerebrovascular haemorrhage, encephalopathy, brain stem compression and thrombosis). Comparison of characteristics of deaths and survivors revealed no significant differences because of small numbers. Compared with women with severe 
Table 3 Unadjusted relative risks of intensive care unit admission by ethnicity

\begin{tabular}{lrrc}
\hline & \multicolumn{1}{c}{$n$} & $(\%)$ & $\mathrm{RR}(95 \% \mathrm{CI})$ \\
\hline Western & 648 & 77.4 & 1 \\
Non-Western & 186 & 22.2 & $1.4(1.2-1.7)$ \\
Morocco & 43 & 5.1 & $1.3(0.9-1.7)$ \\
Turkey & 26 & 3.1 & $1.0(0.7-1.4)$ \\
Surinam & 29 & 3.5 & $1.5(1.1-2.2)$ \\
Dutch Antilles & 14 & 1.7 & $1.7(1.0-2.9)$ \\
Sub-Saharan Africa & 31 & 3.7 & $3.6(2.5-5.1)$ \\
Central Asia & 11 & 1.3 & $1.5(0.8-2.7)$ \\
Eastern Asia & 17 & 2.0 & $2.1(1.3-3.4)$ \\
Unknown & 3 & 0.4 & \\
\hline
\end{tabular}

maternal morbidity who were not admitted to ICU, women admitted to ICU had a significantly higher case fatality rate $(3.4$ vs. $1.1 \%, p<0.001)$.

\section{Discussion}

This report concerns by far the largest prospective cohort of obstetric ICU admissions in the literature. In the only other, comparably large study inclusion was performed retrospectively, with case ascertainment relying on ICD-9 codes [8]. The incidence of 2.4 per 1,000 in The
Netherlands is comparable with other high income countries considering the range of incidences of 2-4 per 1,000 as mentioned by Zeeman [9]. However, the case fatality rate of $3.4 \%$ is well under the average of $6.8 \%$ in other studies $[9,10]$. The average duration of ICU stay was also lower than reported by others ( 3 vs. 5 days) [3, $9,11-22]$, and women seemed to be older (mean age 32 vs. 29 years) $[3,11,13-15,17-19,21-25]$. With respect to the moment of admission, our findings were comparable with other studies. In this study $\mathrm{MOH}$ was diagnosed almost twice as often as on average in other studies (45.5 against 23.6\%), although incidence varied largely from 5 to $53 \%$ [3, 9, 11-27]. On the other hand, respiratory disease and thrombo-embolism were diagnosed less than half as much in our study as compared with others (5.1 vs. $13.3 \%$ and 1.6 vs. $4.2 \%$ ) [3, 11-14, 16-19, 22-27]. Only 20 women were admitted to ICU with peripartum cardiomyopathy ( 1 in 20,000 pregnancies). This is few in light of the reported incidence of 1 in 100 to 1 in 15,000 pregnancies [28]. Differences could be explained by the fact that most other studies were not population based, but mainly from level 3 ICUs. Tertiary care centres receive relatively more women with hypertensive disorders than women with $\mathrm{MOH}$ as this concerns an acute clinical problem that is mostly treated locally. The less frequent diagnosis of hypertensive disorders of pregnancy as compared to the other studies (26.8 vs.

Table 4 Risk indicators for obstetric ICU admission, as compared with non-ICU admission and as compared with the general pregnant population

\begin{tabular}{|c|c|c|c|c|c|c|}
\hline & \multirow{2}{*}{$\begin{array}{l}\text { Obstetric ICU } \\
\text { admission } \\
(n=837) \\
(\%)\end{array}$} & \multicolumn{3}{|c|}{$\begin{array}{l}\text { Severe maternal morbidity } \\
\text { without ICU admission } \\
(n=1,676)\end{array}$} & \multicolumn{2}{|c|}{$\begin{array}{l}\text { The Netherlands, general } \\
\text { pregnant population } \\
(n=358,874)\end{array}$} \\
\hline & & $(\%)$ & $\begin{array}{l}\text { Unadjusted } \\
\text { OR }(95 \% \text { CI) }\end{array}$ & $\begin{array}{l}\text { Adjusted* } \\
\text { OR }(95 \% \text { CI })\end{array}$ & $(\%)$ & $\begin{array}{l}\text { Unadjusted } \\
\text { RR (95\% CI) }\end{array}$ \\
\hline \multicolumn{7}{|l|}{ Patient } \\
\hline \multicolumn{7}{|l|}{ Age } \\
\hline$\geq 35$ years & 29.3 & 27.9 & $1.1(0.9-1.3)$ & & 24.7 & $1.0(0.8-1.1)$ \\
\hline$\geq 40$ years & 5.3 & 4.7 & $1.1(0.8-1.7)$ & & 3.4 & $1.6(1.1-2.1)$ \\
\hline \multicolumn{7}{|l|}{ Body mass index $\left(\mathrm{kg} / \mathrm{m}^{2}\right)$} \\
\hline$<18.5$ (underweight) & 3.8 & 2.4 & $1.6(0.9-2.9)$ & & 3.1 & $1.7(1.2-2.5)$ \\
\hline$\geq 25$ (overweight) & 36.6 & 36.2 & $1.0(0.8-1.3)$ & & 31.7 & $2.0(1.7-2.4)$ \\
\hline$\geq 30$ (obese) & 15.6 & 12.0 & $1.4(1.0-1.8)$ & $1.3(0.9-1.7)$ & 9.8 & $1.7(1.4-2.2)$ \\
\hline \multicolumn{7}{|l|}{ Pregnancy } \\
\hline Parity $\geq 3$ & 6.7 & 4.2 & $1.6(1.1-2.3)$ & $1.6(1.0-2.6)$ & 5.0 & $1.4(1.0-1.8)$ \\
\hline Prior caesarean delivery & 14.7 & 21.1 & $0.7(0.5-0.8)$ & $0.5(0.4-0.7)$ & 10.1 & $1.5(1.3-1.9)$ \\
\hline Artificial reproduction techniques: IVF/ICSI & 5.6 & 4.4 & $1.3(0.9-1.9)$ & & 1.9 & $3.0(2.2-4.0)$ \\
\hline Multiple pregnancy & 8.4 & 7.9 & $1.1(0.8-1.4)$ & & 1.7 & $5.2(4.1-6.6)$ \\
\hline Initial antenatal care by obstetrician & 38.0 & 37.4 & $1.0(0.9-1.2)$ & & 14.3 & $3.7(3.5-3.9)$ \\
\hline \multicolumn{7}{|l|}{ Delivery } \\
\hline Home delivery & 3.5 & 8.2 & $0.4(0.3-0.6)$ & $0.4(0.2-0.7)$ & 30.0 & $0.1(0.05-0.1)$ \\
\hline Induction of labour & 28.6 & 25.1 & $1.2(1.0-1.4)$ & $1.6(1.2-2.0)$ & 12.5 & $2.8(2.4-3.3)$ \\
\hline Caesarean delivery overall & 52.9 & 37.6 & $1.9(1.6-2.2)$ & $1.5(1.1-2.0)$ & 13.0 & $7.7(6.7-8.8)$ \\
\hline Prelabour caesarean delivery & 31.2 & 16.9 & $2.2(1.8-2.7)$ & $2.0(1.5-2.8)$ & 5.9 & $7.2(6.3-8.4)$ \\
\hline Ventouse/forceps extraction & 10.4 & 13.5 & $0.7(0.6-1.0)$ & $0.8(0.5-1.1)$ & 8.6 & $1.3(1.1-1.7)$ \\
\hline
\end{tabular}

$O R$ odds ratio, $C I$ confidence interval

*All significant factors in univariable analysis were included in the multivariable logistic regression model. Significant values are in bold 
$36.3 \%)$ was surprising in the light of the elevated incidence of eclampsia recently found in the Netherlands [29]. This possibly reflects the underestimation of the risk of severe preeclamptic conditions in the Netherlands [30]. Over 60 percent received packed cells, which is more than others previously reported (47.3\% in Canada and 32.0\% in the UK) $[12,20]$. As could be expected, we saw that tertiary care centres, high-level ICUs and high-volume hospitals treated more severely ill women with cardiac, liver/pancreatic, cerebral, thrombo-embolic and septic diseases as compared to general hospitals, level 1 ICUs and low-volume hospitals. Women who had their antenatal care with an obstetrician for any preexisting medical or obstetric condition had an elevated risk of being admitted to ICU, whereas women who delivered at home under supervision of the midwife had a decreased risk. These findings support the proper functioning of the system of selection between low- and high-risk pregnancies used in the Netherlands.

Another important finding in this study is the fact that only one-third of all cases of severe maternal morbidity in the Netherlands were admitted to an ICU. The same was reported by Brace et al. [31]. Therefore, obstetric ICU admission alone is not a good surrogate for severe maternal morbidity. However, it seems appropriate to use ICU admission to describe maternal characteristics and associated factors, because we found no differences between women who were and were not admitted to ICU. Even so, we can say that the most severe cases of severe maternal morbidity are generally included, as illustrated by the significantly higher case fatality rate and higher number of performed caesarean sections for maternal conditions of ICU women as compared to non-ICU women.

Since women with severe maternal morbidity had a baseline risk, odds ratios for ICU versus non-ICU women were not that high. Nevertheless, we found induction of labour and caesarean section to be adjusted risk factors. The protective effect of a previous caesarean section is probably caused by the fact that many of these women were included because of uterine rupture, a condition that rarely necessitates maternal ICU admission.

With abortion being legal in the Netherlands, septic abortion proved to be rare. One death among four women with septic abortion was found during the study period as compared to 63 in a 10-year unicentre study from Argentina with a comparable case fatality rate [32].

The main limitation of this study is that we were not able to correct population-based risk indicators for possible confounders as individual characteristics of the reference population were not available. Some relative risks are obviously confounded. The high relative risk among women who delivered by caesarean is probably confounded as caesarean delivery could be the consequence of the underlying disease for which the mother was admitted rather than the risk factor. This could also be true for induction of labour.
ICU admission is a management-based criterion and therefore by definition leads to inclusion bias. This is especially the case for tertiary care centres, where the threshold for ICU admission is high due to the presence of obstetric high care units. These women would probably have been admitted to the ICU in other hospitals. Furthermore, we saw that the threshold for ICU admission was sometimes low in low-volume maternity units due to the fact that local protocols require intravenous therapy of pre-eclampsia to be monitored at an ICU due to logistic reasons. This probably also explains the relatively long duration of ICU stay in low-volume hospitals and the relatively high share of admissions for hypertensive disorders at level I ICUs.

Finally, results of the present study cannot be merely extrapolated to other countries. This was illustrated by Munnur et al. [33] reporting marked differences in medical diseases, organ failure and intensive care needs between a developed and a developing country.

As shown, the management of critically ill women during pregnancy, delivery and puerperium is difficult and requires specific knowledge of the physiology and pathology of pregnancy. Therefore, both obstetrician and intensivist/anaesthesist should always be involved in the management of women admitted to the ICU. As obstetric ICU admission is a rare event in Western countries, exposure of obstetricians and intensivists/anaesthesists is low. This would plea for centralisation of obstetric care, which is a very current issue in the Netherlands. Although underexposure to rare but life-threatening complications might affect quality of care, this has to be balanced against the disadvantage of larger distances between obstetric services, which involves many more pregnant women.

\section{Conclusions}

ICU admission complicates $0.24 \%$ of pregnancies in the Netherlands. Although illnesses are generally very serious, the case fatality rate is relatively low as compared to non-pregnant patients admitted to ICU. Proper management of obstetric ICU admissions requires intensive cooperation of intensivist/anaesthesist and obstetrician. Since two-thirds of all women with severe maternal morbidity in the Netherlands were not admitted to the ICU, ICU admission is not a good parameter to assess the incidence of severe maternal morbidity in a specific population. It is, however, a good indicator of the most severe cases of maternal morbidity.

Acknowledgments The study was supported by a grant of the The Netherlands Organisation for Health Research and Development (ZonMw 3610.0024) and the Matty Brand Foundation.

We thank the members of the LEMMoN expert panel for their contribution: K.W.M. Bloemenkamp (Leiden University Medical Centre), H.W. Bruinse and A. Kwee (University Medical Centre 
Utrecht), E.A.P. Steegers and W. Visser (Erasmus Medical Centre), G.D. Mantel (Isala Klinieken), M.G. van Pampus (University Medical Centre Groningen), J.I.P. de Vries (VU University Medical Centre). We thank R. Rodrigues Pereira for his cooperation in establishing the national surveillance system (NSCOG)

We also greatly thank all local coordinators who kindly participated: Alkmaar: C. Akkerman (Medisch Centrum Alkmaar) Almelo: P.J.A. van der Lans (Ziekenhuis Groep Twente), Almere: G. Kleiverda (Flevoziekenhuis), Amersfoort: E. Lenters (Meander Medisch Centrum), Amstelveen: C.L. van der Wijden (Ziekenhuis Amstelveen), Amsterdam: M.H.B. Heres (Sint Lucas Andreas Ziekenhuis), J.I.P. de Vries, J.H.K. van Brummelen-Joosten (VU University Medical Centre), J.M.M. van Lith (Onze Lieve Vrouwe Gasthuis), M. Pel (Academic Medical Centre), B.M.I. Doekhie (BovenIJ Ziekenhuis), E.D. van Oudgaarden (Slotervaartziekenhuis), Apeldoorn: W.A. Spaans (Gelre Ziekenhuizen), Arnhem: K. de Boer (Ziekenhuis Rijnstate), Assen: M.W. Glas (Wilhelmina Ziekenhuis), Bergen op Zoom: J. Ramondt (Ziekenhuis Lievensberg), Beverwijk: J. Roest (Rode Kruis Ziekenhuis), Blaricum: J.J. Dieles (Tergooiziekenhuizen), Boxmeer: A.G. Minkhorst (Maasziekenhuis), Breda: D.N.M. Papatsonis (Amphia Ziekenhuis), Capelle a/d IJssel: W.F. Lam (IJsselland Ziekenhuis), Delft: H.A. Bremer (Reinier de Graaf Groep), Delfzijl: A. van Zanten (Delfzicht Ziekenhuis), Den Bosch: H.P. Oosterbaan, M.H.H.M. Kerkhof (Jeroen Bosch Ziekenhuis), Den Haag: F.T.H. Lim, J. van Dillen (HagaZiekenhuis), C.A.G. Holleboom (Ziekenhuis Bronovo), C.B. Vredevoogd (Medisch Centrum Haaglanden), Den Helder: J. Friederich (Gemini Ziekenhuis), Deventer: J.M. Schierbeek (Deventer Ziekenhuis), Dirksland: N.P.J. Vreuls (Van Weel-Bethesda Ziekenhuis), Doetinchem: F.J.L. Reijnders (Slingeland Ziekenhuis), Dokkum: M.M. Henselmans (Ziekenhuis Talma-Sionsberg), Dordrecht: B.M.C. Akerboom (Albert Schweitzer Ziekenhuis), Drachten: P.J. van den Hurk (Ziekenhuis Nij Smellinghe), Ede: H.J. Kwikkel (Ziekenhuis Gelderse Vallei), Eindhoven: S.M. I. Kuppens (Catharina Ziekenhuis), Emmen: J.M. Burggraaff (Scheperziekenhuis), Enschede: P.R. Poeschmann (Medisch Spectrum Twente), Geldrop: A. Neijmeijer-Leloux (Sint Annaziekenhuis), Goes: M. Baaij (Oosterscheldeziekenhuizen), Gorinchem: R. Euser (Rivas Medizorg), Gouda: J. C.M. van Huisseling (Groene Hart Ziekenhuis), Groningen: G.G. Zeeman (University Medical Centre Groningen), A.J. van Loon (Martini Ziekenhuis), Haarlem: J. Clements (Kennemer Gasthuis), Hardenberg: P.J.M. Baudoin (Röpcke Zweers Ziekenhuis), Harderwijk: R.L. van de Pavert (Ziekenhuis Sint Jansdal), Heerenveen: G.H. Weenink (Ziekenhuis Tjongerschans), Heerlen: F.J.M.E. Roumen (Atrium Medisch Centrum), Helmond: J.H.J.M. van der Avoort (Elkerliek Ziekenhuis), Hengelo: P. Paaymans (Streekziekenhuis MiddenTwente), Hilversum: M. van Hoven (Tergooiziekenhuizen),
Hoofddorp: A. Lub, M. de Lange (Spaarne Ziekenhuis), Hoogeveen: M. Koppe (Ziekenhuis Bethesda), Hoorn: T.W.A. Huisman (Westfries Gasthuis), Leeuwarden: J.G. Santema (Medisch Centrum Leeuwarden), Leiden: J.C.M. Spiekerman (Diaconessenhuis), K.W.M. Bloemenkamp (Leiden University Medical Centre), Leiderdorp: O.J.A. Mattheussens (Rijnland Ziekenhuis), Lelystad: C.N. de Boer (IJsselmeerziekenhuis, Lokatie Lelystad), Maastricht: C. Willekes (University Hospital Maastricht), Meppel: G.M. Vermeulen (Diaconessenhuis), Nieuwegein: E. van Beek (Sint Antonius Ziekenhuis), Nijmegen: D.H. Schippers (Canisius-Wilhelmina Ziekenhuis), Nijmegen: J.W.T. Creemers (Radboud University Nijmegen Medical Centre), Oss: M.A.L. Verwij-Didden (Ziekenhuis Bernhoven), Purmerend: H. Prins (Waterlandziekenhuis), Roermond: L.C.G. Wetzels (Laurentius Ziekenhuis), Roosendaal: R. Pal (Franciscus Ziekenhuis), Rotterdam: G.C.H. Metz (Ikazia Ziekenhuis), P.E. van der Moer (Medisch Centrum Rijnmond Zuid), N. van Gemund (Sint Franciscus Gasthuis), J.J. Duvekot (Erasmus Medical Centre), Sittard: J. Alleman (Maaslandziekenhuis), Sneek: E.A. van Eyk (Antonius Ziekenhuis), Spijkenisse: F.W. Worst (Ruwaard van Putten Ziekenhuis), Stadskanaal: G.W. Oostendorp (Refaja Ziekenhuis), Terneuzen: J.W.E. Voitus van Hamme (Ziekenhuis Zeeuws-Vlaanderen), Tiel: R. Hardeman (Ziekenhuis Rivierenland), Tilburg: C.M. van Oirschot (Sint Elisabeth Ziekenhuis), A.E.M. Roosen (TweeSteden Ziekenhuis), Utrecht: J. Lange (Mesos Medisch Centrum), Dr. H.W. Bruinse (University Medical Centre Utrecht), N.W.E. Schuitemaker (Diakonessenhuis), Veghel: Y.H.C.M. van Zwam (Ziekenhuis Bernhoven), Veldhoven: B.W.J. Mol (Máxima Medisch Centrum), Venlo: C.G.M. de Rooy (Vie Curi Medisch Centrum Noord Limburg), Vlaardingen: R.J.H. Oostendorp (Vlietland Ziekenhuis), Vlissingen: S. de Boer (Ziekenhuis Walcheren), Weert: W.E. Nolting (Sint Jansgasthuis), Winschoten: P.H. van Drooge (Sint Lucas Ziekenhuis), Winterswijk: D.M.R. van der Borden (Streekziekenhuis Koningin Beatrix), Woerden: I.H. Goedhuis (Hofpoort Ziekenhuis), Zaandam: K. Brouwer (De Heel Zaans Medisch Centrum), Zevenaar: R.J.C. Mouw (Ziekenhuis Zevenaar), Zoetermeer: J.M.T. Roelofsen (Lange Land Ziekenhuis), Zutphen: Y.A.J.M. Dabekausen (Gelre Ziekenhuizen), Zwolle: J. van Eyck (Isala Klinieken).

Conflict of interest statement The authors state that there are no competing interests.

Open Access This article is distributed under the terms of the Creative Commons Attribution Noncommercial License which permits any noncommercial use, distribution, and reproduction in any medium, provided the original author(s) and source are credited.

\section{References}

1. Schutte JM, de Boer K, Briët JW, Pel M, Santema JG, Schuitemaker NEW, Steegers EAP, Visser W, van Roosmalen $\mathrm{J}$ (2005) Maternal mortality in the Netherlands: the tip of the iceberg. Ned Tijdschr Obstet Gynecol 118:89-91
2. Lewis G (ed) 2007. The Confidential Enquiry into Maternal and Child Health (CEMACH). Saving mother's lives: reviewing maternal deaths to make motherhood safer-2003-2005. The seventh report on confidential enquiries into maternity deaths in the United Kingdom, CEMACH, London
3. Keizer JL, Zwart JJ, Meerman RH, Harinck BI, Feuth HD, van Roosmalen J (2006) Obstetric intensive care admissions: a 12-year review in a tertiary care centre. Eur J Obstet Gynecol Reprod Biol 128:152-156

4. Zwart JJ, Richters JM, Ory F, de Vries JIP, Bloemenkamp KWM, van Roosmalen J (2008) Severe maternal morbidity during pregnancy, delivery and puerperium in the Netherlands: a nationwide populationbased study of 371,000 pregnancies. BJOG 115:842-850 
5. Dutch Health Care Inspection: Annual report performance indicators hospitals PI 12. http://www.igz.nl/publicaties/ jaarrapportages/ziekenhuizen. Accessed 19 June 2008

6. Central Bureau of Statistics Netherlands (CBS): Statline. http://www.cbs.nl/ en-GB/. Accessed 2 Oct 2007

7. Landelijke Verloskunde Registratie (Dutch Perinatal Database, LVR): The Netherlands Perinatal Registry, Prismant

8. Panchal S, Arria AM, Harris AP (2000) Intensive care utilization during hospital admission for delivery: prevalence, risk factors, and outcomes in a statewide population. Anesthesiology 92:1537-1544

9. Zeeman GG (2006) Obstetric critical care: a blueprint for improved outcomes. Crit Care Med 34:S208-S214

10. Sirio CA, Shepardson LB, Rotondi AJ, Cooper GS, Angus DC, Harper DL, Rosenthal GE (1999) Community-wide assessment of intensive care outcomes using a physiologically based prognostic measure: implications for critical care delivery from Cleveland Health Quality Choice. Chest 115:793-801

11. Afessa B, Green B, Delke I, Koch K (2001) Systemic inflammatory response syndrome, organ failure, and outcome in critically ill obstetric patients treated in an ICU. Chest 120:1271-1277

12. Baskett TF, Sternadel J (1998) Maternal intensive care and near-miss mortality in obstetrics. Br J Obstet Gynaecol 105:981-984

13. Cohen J, Singer P, Kogan A, Hod M, Bar J (2000) Course and outcome of obstetric patients in a general intensive care unit. Acta Obstet Gynecol Scand 79:846-850

14. el Solh AA, Grant BJ (1996) A comparison of severity of illness scoring systems for critically ill obstetric patients. Chest 110:1299-1304

15. Gilbert TT, Smulian JC, Martin AA, Ananth CV, Scorza W, Scardella AT, Critical Care Obstetric Team (2003) Obstetric admissions to the intensive care unit: outcomes and severity of illness. Obstet Gynecol 102:897-903
16. Hazelgrove JF, Price C, Pappachan VJ, Smith GB (2001) Multicenter study of obstetric admissions to 14 intensive care units in southern England. Crit Care Med 29:770-775

17. Karnad DR, Lapsia V, Krishnan A, Salvi VS (2004) Prognostic factors in obstetric patients admitted to an Indian intensive care unit. Crit Care Med 32:1294-1299

18. Kilpatrick SJ, Matthay MA (1992) Obstetric patients requiring critical care. A 5-year review. Chest 101:14071412

19. Mahutte NG, Murphy-Kaulbeck L, Le Q, Solomon J, Benjamin A, Boyd ME (1999) Obstetric admissions to the intensive care unit. Obstet Gynecol 94:263-266

20. Murphy DJ, Charlett P (2002) Cohort study of near-miss maternal mortality and subsequent reproductive outcome. Eur J Obstet Gynecol Reprod Biol 102:173-178

21. Selo-Ojeme DO, Omosaiye M, Battacharjee P, Kadir RA (2005) Risk factors for obstetric admissions to the intensive care unit in a tertiary hospital: a case-control study. Arch Gynecol Obstet 272:207-210

22. Tang LC, Kwok AC, Wong AY, Lee YY, Sun KO, So AP (1997) Critical care in obstetrical patients: an 8-year review. Chin Med J (Engl) 110:936941

23. Bouvier-Colle MH, Salanave B, Ancel PY, Varnoux N, Fernandez H, Papiernik E, Bréart G, Benhamou D, Boutroy P, Caillier I et al (1996) Obstetric patients treated in intensive care units and maternal mortality. Regional Teams for the Survey. Eur J Obstet Gynecol Reprod Biol 65:121-125

24. Loverro G, Pansini V, Greco P, Vimercati A, Parisi AM, Selvaggi L (2001) Indications and outcome for intensive care unit admission during puerperium. Arch Gynecol Obstet 265:195-198

25. Quah TC, Chiu JW, Tan KH, Yeo SW, Tan HM (2001) Obstetric admissions to the intensive therapy unit of a tertiary care institution. Ann Acad Med Singapore 30:250-253
26. Ali E, Bechir K, Badis CM, Nabil M, Hanene E, Mourad B, Salah HM, Hayen M, Ezzeddine S, Hela C (2005) The managment of serious pregnant disease in the intensive care unit. Tunis Med 83:87-90

27. Zeeman GG, Wendel GD Jr, Cunningham FG (2003) A blueprint for obstetric critical care. Am J Obstet Gynecol 188:532-536

28. de Beus E, van Mook WN, Ramsay G, Stappers JL, van der Putten HW (2003) Peripartum cardiomyopathy: a condition intensivists should be aware of. Intensive Care Med 29:167-174

29. Zwart JJ, Richters A, Ory F, de Vries JIP, Bloemenkamp KWM, van Roosmalen J (2008) Eclampsia in the Netherlands. Obstet Gynecol 112:820827

30. Schutte JM, Schuitemaker NW, van Roosmalen J, Steegers EA, Dutch Maternal Mortality Committee (2008) Substandard care in maternal mortality due to hypertensive disease in pregnancy in the Netherlands. BJOG 115(6):732-736

31. Brace V, Penney G, Hall M (2004) Quantifying severe maternal morbidity: a Scottish population study. BJOG 111:481-484

32. Finkielman JD, De Feo FD, Heller PG, Afessa B (2004) The clinical course of patients with septic abortion admitted to an intensive care unit. Intensive Care Med 30:1097-1102

33. Munnur U, Karnad DR, Bandi VD, Lapsia V, Suresh MS, Ramshesh P, Gardner MA, Longmire S, Guntupalli KK (2005) Critically ill obstetric patients in an American and an Indian public hospital: comparison of casemix, organ dysfunction, intensive care requirements, and outcomes. Intensive Care Med 31:1087-1094

34. Lewinsohn G, Herman A, Leonov Y, Klinowski E (1994) Critically ill obstetrical patients: outcome and predictability. Crit Care Med 22:14121414 